\title{
THE COMPACTNESS INDICATORS OF SOLIDS APPLIED TO ANALYSIS OF GEOMETRIC EFFICIENCY OF BUILDINGS
}

\author{
Edwin KOŹNIEWSKI@1* ${ }^{*}$, Antonina ŻABA@2 2 , Piotr DUDZIK@2 \\ ${ }^{1}$ Bialystok University of Technology, 15-351 Biatystok, ul. Wiejska 45E, Poland \\ ${ }^{2}$ Silesian University of Technology, 44-100 Gliwice, ul. Krzywoustego 7, Poland
}

Received 12 February 2019; accepted 25 March 2019

\begin{abstract}
The authors redefine and generalize the so-called relative ratio of compactness of solid with respect to sphere and cube introduced by Mahdavi and Gurtekin. The authors propose such new indicators as a relative ratio of solid compactness in the shape of a prism-shaped solid related to a cuboid with a square base and a given height (e.g. the height of the analyzed storey), a solid compactness indicator defined for the basis of the prism relative to the square. They introduce also other indicators: a relative defect of the perimeter and area. The test of indicators formulated and described in the paper was carried out in two groups of buildings: existing (spotted locally) and those whose designs can be found in the selected catalog available on the website. In addition to the compactness ratios calculated for existing and designed buildings, an analysis of the size of the indicators for the adopted building research models was made. Proposed indicators allow for a description of the compactness of the building model with an indication of the deviation from the real ideal solid. The introduced geometric determinants of solids may be useful in the initial phase of searching for satisfactory design solutions.
\end{abstract}

Keywords: compactness of solid, geometric compactness of building, geometric efficiency of building, compactness indicator, relative ratio of compactness, cuboid, relative defect of perimeter, relative defect of area.

\section{Introduction}

At the beginning, we give an understanding of the most important terms used in this work. The geometric efficiency of a building that meets the assumed size parameters (cubic capacity, usable area) is a set of geometric features that make the building functional, economical (with low energy demand) in construction and maintenance, safe in use and aesthetic. An important geometric feature of the building is its compactness. By building compactness we mean the compactness of the solid which is an isometric geometrical model of the building envelope or its part. The geometric compactness of a rigid solid is the relationship between the enclosing surface and volume. The classical measure of compactness is defined by the dimensionless ratio (area) $)^{3} /(\text { volume })^{2}$ (Bribieska, 2000). In this work as a measure of compactness, so-called compactness indicators, defined by the authors or quoted from the literature, will be used.

Energy consumption in the course of buildings' lifecycle is one of the most important criteria of currently designed buildings. The issues of optimizing energy-efficient buildings (through the search for adequate geometric de- scription) have long been the subject of research in many publications, to name but a few (Fokin, 2006; Markus \& Morris, 1980; Menkhoff, Blum, Trykowski, Wente, \& Zapke, 1983; Adamski, 1994; Depecker, Menezo, Virgone, \& Lepers, 2001; Mahdavi \& Gurtekin, 2001, 2002; Behsh, 2002; Jedrzejuk \& Marks, 2002; Ourghi, Al-Anzi, \& Krarti, 2007; Tuhus-Dubrow \& Krarti, 2010; Parasonis, Keizikas, Endriukaityte, \& Kalibatiene, 2012; Geletka \& Sedláková, 2012; McKeen \& Fung, 2014; Elango \& Devadas, 2014; Allouhi et al., 2015; Rodrigues, Amaral, Gaspar, \& Gomes, 2015; Almumar, 2016; Raof, 2017; Lim \& Kim, 2018).

Already in 1934 in a monograph (Fokin, 2006) the shape of a building with a given volume was optimized on the basis of the minimum thermal energy loss criterion and the result was a building in the shape of a sphere. In the paper (Menkhoff et al., 1983) analyzed the geometry of the building structure and it was where the term geometric compactness as the quotient of the external partitions (A) and building volume (V) was introduced for the first time in literature. The analysis of the compactness was performed by studying a solid composed of four identical

${ }^{\star}$ Corresponding author. E-mail: e.kozniewski@pb.edu.pl 
cubes with edges a in different configurations. Ratios from $4 / \mathrm{a}$ to $14.1 / \mathrm{a}$ were obtained.

Behsh (2002) stated that the $\mathrm{A} / \mathrm{V}$ ratio is not a valid indicator of thermal efficiency of buildings with complex plans.

These results:

1. Testify to the validity of the geometrical study of the compactness of the designed building, since the ratio $\mathrm{A} / \mathrm{V}$ can have such a large (350\%) dispersion;

2. Indicate imperfections of the $\mathrm{A} / \mathrm{V}$ ratio whose values depend on the adopted units.

Markus and Morris (1980) defined the so-called "Ratio of Change" (ROC). The "Ratio of Change" has been calculated by comparing the surface area to volume ratio of a building to that of a cube with the same volume (Markus \& Morris, 1980). Mahdavi and Gurtekin (2001) used the socalled "Relative Compactness" $(R C)$ with respect to sphere (cube) defined as the ratio between compactness $(\mathrm{A} / \mathrm{V})_{\text {sph }}$ and $(\mathrm{A} / \mathrm{V})_{\text {build }}\left((\mathrm{A} / \mathrm{V})_{\text {cube }}\right.$ and $\left.(\mathrm{A} / \mathrm{V})_{\text {build }}\right)$. Using this indicator, objects of various shapes were studied (Mahdavi \& Gurtekin, 2001; Pessenlehner \& Mahdavi, 2003; Geletka \& Sedláková, 2012). Bostancioğlu (2010) uses the ratio of external wall area to floor area (EWA/FA). Ourghi et al. (2007) and Tuhus-Dubrow and Krarti (2010) use the relative compactness $(R C)$ coefficient, which express the ratio between the shape coefficient of a designed building $(\mathrm{A} / \mathrm{V})_{\text {des }}$ and the shape coefficient of a reference (rectangular) building with an equal volume (A/V) ref. Parasonis et al. (2012) proposed several improvements the last ratio. Instead of the $\mathrm{A} / \mathrm{V}$ ratio, $\mathrm{A} / \mathrm{S}$ is assumed, where $\mathrm{A}$ is the area of the external envelope of a building and $\mathrm{S}$ is the useful (heated) area, showing how efficiently geometry is utilised. Authors proposed that the non-dimensional A/S ratio can be referred to as the concept of "Geometric Efficiency" $(G E)$. As a result of the analysis of exemplary buildings, it turned out that both compact and non-compact buildings can have the same GE values. Therefore, they proposed adopting relative geometric efficiency $(R G E)$ as a ratio $G E / G E_{\text {ref }}$, where $G E_{\text {ref }}=(\mathrm{A} / \mathrm{S})_{\text {ref }}$ is the limit (reference) expression of geometric efficiency that is the closest to a cubic building (reference building) that accommodates a given area; $R G E$ shows how far $G E$ of a designed building deviates from the $G E_{\text {ref }}$ value of the reference building (Parasonis et al., 2012). The area research is the search for ways to assess the geometrical content of the designed building (Hemsath \& Bandhosseini, 2015; Raof, 2017). Often these are quite complicated algorithms implemented as computer programs (Rodrigues et al., 2015). The search for the best shape of the building is still valid (Almumar, 2016; Lim \& Kim, 2018). The authors are looking for, but in our opinion do not find a satisfactory solution. Such indicators, in contrast to the $\mathrm{A} / \mathrm{V}$ ratio, are already non-quantified numbers and to a certain degree normalized, however, they do not have the characteristics to express the deviation of the compactness of a given solid from the reference (model) in percentage points. In addition, the reference to the cube still has some imperfection, namely the height of the storeys of a single-family house is basically fixed and ranges from $2.50[\mathrm{~m}]$ to 3.30 [m] (N. Neufert \& P. Neufert, 2012). Then the height of the multi-storey house is a particular height. Imposing the "artificial" height resulting from the modeling of the cube is a distortion of the measure of the building's compactness. The concept of the reference building also remains undetermined.

The main purpose of the work is to generalize the compactness indicators used by Mahdavi and Gurtekin (2001, 2002) and to introduce new geometric characteristics of the building, which allow to improve the description of the shape of the building (compactness of the building) from the point of view of its geometrical efficiency.

\section{A new approach to the geometric description of the shape of a building}

Koźniewski in his work (Koźniewski, 2007) described the properties of rectangular polygons, and later in his paper (Koźniewski, 2015) introduced the concept of the relative defect of the area and perimeter as well as the span of the polygon. These results have become an inspiration for further search for other indicators, more accurately characterizing the geometric compactness of solids.

In this paper, the authors propose such new indicators as a relative ratio of solid compactness in the shape of a prism-shaped solid related to a cuboid with a square base and a given height (e.g. the height of the analyzed storey), a solid compactness indicator defined for the basis of the prism relative to the square (Koźniewski, Żaba, \& Dudzik, 2015).

Then, in order to "generalize" the so-called defect of the perimeter described in the paper (Koźniewski, 2015), the authors introduce a new relative defect of the perimeter with parameter $k$ ( $k$ - ratio of the length of the sides of the rectangle) in relation to the reference rectangle (square for $k=1)$.

The object of research in this study is the geometric compactness of a detached house on the projection of a rectangular polygon, hitherto understood as $\mathrm{A} / \mathrm{V}$ (the quotient of the surface area of its external walls and volume). Calculations were carried out for simplified geometrical models of these buildings, mainly in relation to the rectangular part of the body of the building with the basis of a rectangular polygon, and also in relation to the projection of the building itself. The general scheme of geometric compactness of the building is shown in Figure 1. A symbolic illustration of the indicators introduced in the work and explanations of meanings of acronyms used in the paper are provided in Tables 1, 2 and 3, respectively.

Regarding the shape of the building's projection, from articles by Feather (1996) and Steadman (2006), we find out why the projections of a building in the form of a polygon are the most popular. In the catalogs of finished designs, it can be noticed that the most popular design is the one whose projection contains only concave angles $\left(270^{\circ}\right)$ and convex angles $\left(90^{\circ}\right)$. Designs that do not fit into this group usually have in their outline only some additional 


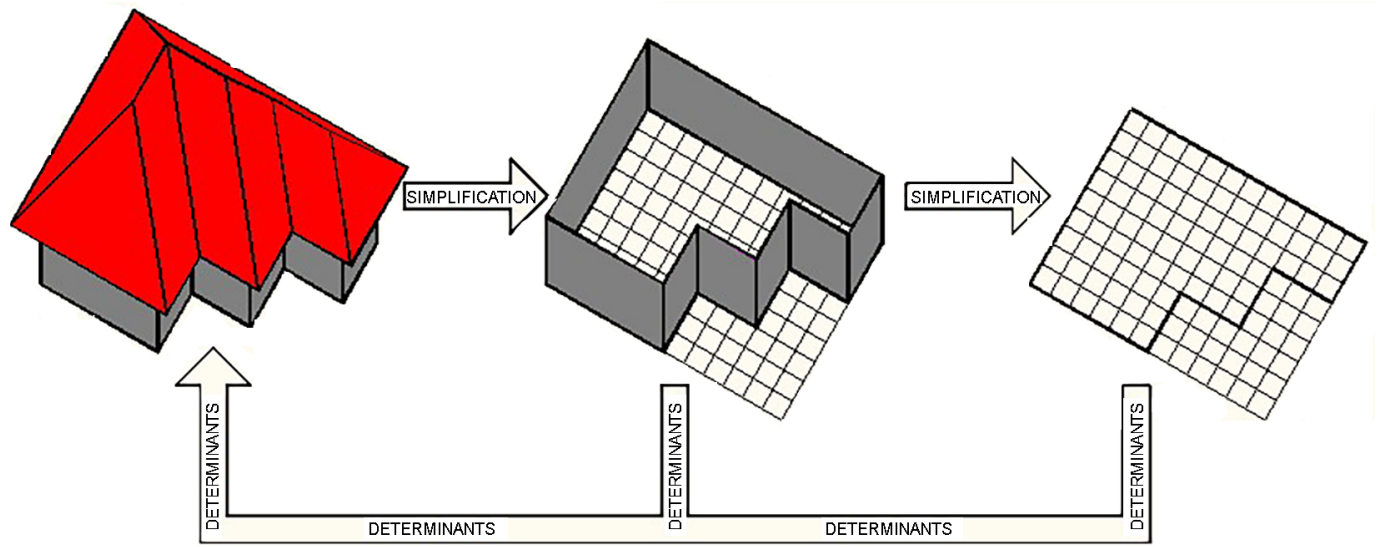

Figure 1. General research scheme of the geometric compactness of a building

Table 1. Symbolic illustration of geometric compactness indicators for $R C_{c u b e}$ and $R C_{c d}$ building solids

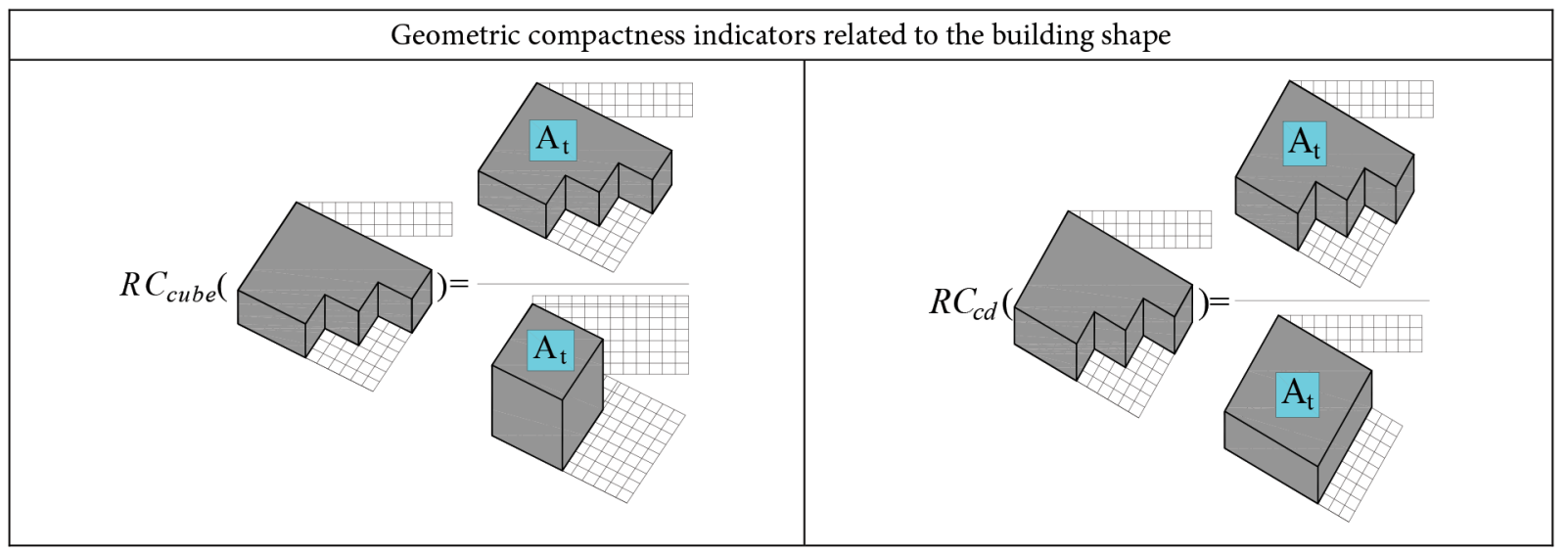

Table 2. Symbolic illustration of geometric compactness indices for the outline of the building $R C_{s q}, R D P_{1}, R D A, R D A^{\prime}$

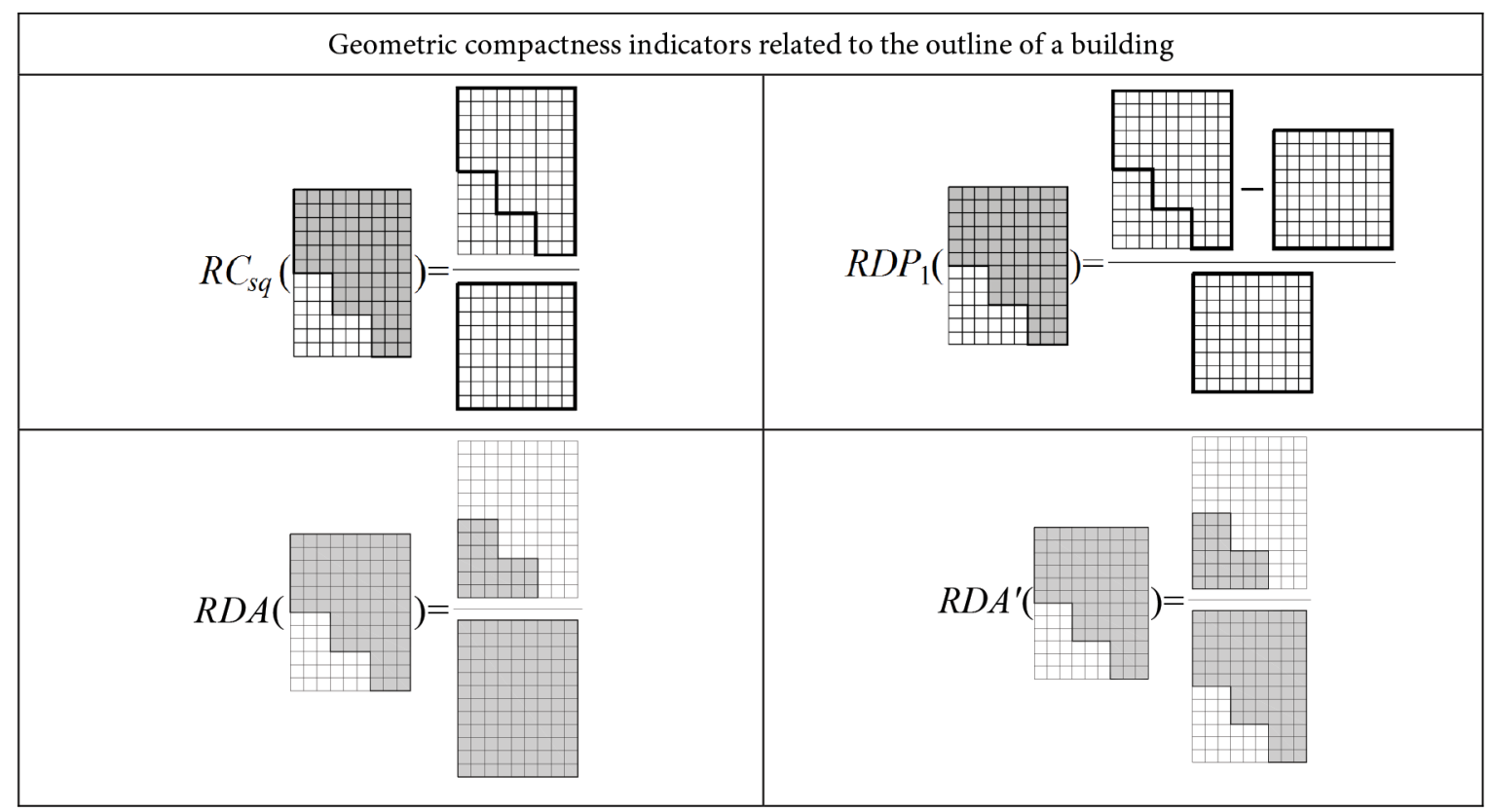


Table 3. List of acronyms used in paper

\begin{tabular}{|c|c|}
\hline Acronym & Explaining of the meaning of acronym \\
\hline S & Solid (understood as a simple prism with base B and height $h$ ) \\
\hline $\mathrm{B}$ & Base of solid \\
\hline $\mathrm{F}$ & Figure (planar region) \\
\hline$A_{t}(S)$ & Total area of a solid S \\
\hline $\mathrm{V}(\mathrm{S})$ & Volume of solid S \\
\hline $\mathrm{S}_{\text {pat }}$ & Pattern solid (a reference solid) \\
\hline$R C_{\text {Spat }}$ & Relative compactness of solid S with respect to reference solid $S_{\text {pat }}$ \\
\hline$R C_{\text {cube }}^{*}$ & Relative compactness of solid S with respect to a cube (in the sense Mahdavi \& Gurtekin, 2002) \\
\hline$R C_{\text {cube }}$ & Relative compactness of solid S with respect to a cube \\
\hline$R C_{\text {sphere }}^{*}$ & Relative compactness of solid S with respect to a sphere (in the sense Mahdavi \& Gurtekin, 2002) \\
\hline$R C_{\text {Sphere }}$ & Relative compactness of solid S with respect to a sphere \\
\hline$A_{b}(B)$ & Area of the base B of the solid S \\
\hline $\mathrm{P}_{\mathrm{b}}(\mathrm{B})$ & Perimeter of the base B of the solid S \\
\hline$R C_{c d}$ & Relative compactness indicator of solid S with respect to the cuboid \\
\hline$R C_{s q}$ & Relative compactness indicator of figure B with respect to the square \\
\hline $\mathrm{R}_{\mathrm{P}}$ & Rectangular polygon \\
\hline $\mathrm{R}$ & Rectangle \\
\hline$\Delta \mathrm{P}_{\mathrm{b}}\left(\mathrm{R}_{\mathrm{P}}\right)$ & Perimeter defect (defect of perimeter of a rectangular polygon $R_{P}$ with respect to $R$ ) \\
\hline$\Delta \mathrm{A}_{\mathrm{b}}\left(\mathrm{R}_{\mathrm{P}}\right)$ & Area defect (defect of area of a rectangular polygon $R_{P}$ with respect to $R$ ) \\
\hline$R D A$ & Relative defect of area (of $R_{P}$ with respect to $R$ ) \\
\hline$R D A^{\prime}$ & Relative defect of area (of $R_{P}$ with respect to $R_{P}$ ) \\
\hline$R D P$ & Relative defect of perimeter (of $R_{P}$ ) \\
\hline $\mathrm{R}_{k}$ & Reference rectangle with the ratio of sides equal to $k$ \\
\hline $\mathrm{R}_{1}$ & Square (a reference rectangle with the ratio of sides equal to 1 ) \\
\hline$R D P_{k}$ & Relative defect of perimeter (with respect to $\mathrm{R}_{k}$ ) \\
\hline$R D P_{1}$ & Relative defect of perimeter (with respect to a square $R_{1}$ ) \\
\hline
\end{tabular}

elements (e.g. bay windows in the shape of a trapezoid or circular section) that do not allow them to qualify for the category in question. These deviations can be easily converted so that the outline can be considered as a rectangular polygon. Such a change will not be of significant importance in the analysis of the functional system, usable area and the amount of materials used to build the considered building.

\section{The compactness of the solid with respect to a cube and sphere}

In their work Mahdavi and Gurtekin (2002), the authors examined the compactness of buildings in relation to two solids with the best compactness. As a measure, they proposed the so-called relative compactness indicator of the solid with respect to the sphere 


$$
R C_{\text {sphere }}^{*} \cong 4,84 \mathrm{~V}^{\frac{2}{3}} \mathrm{~A}^{-1},
$$

and with respect to the cube

$$
R C_{\text {cube }}^{*} \cong 6 \mathrm{~V}^{\frac{2}{3}} \mathrm{~A}^{-1} \text {. }
$$

The numbers 6 and 4, 84, appearing in Eqns (1) and (2), directly indicate the solid relative to which the relative compactness indicator is calculated. Such a description, according to the authors of this work, does not give the possibility of a direct interpretation of the values of indicators. No wonder, why the authors Mahdavi and Gurtekin (2002) suggest transforming the value of the $R C_{\text {cube }}^{*}$ indicator into a seven-point scale. They adopted the following scales of assessment (semantic differential for the subjective evaluation of the compactness shape): highly non-compact, non-compact, somewhat (fairly) non-compact, neutral, somewhat (fairly) compact, compact, highly compact. However, the indicators of relative compactness (applied for the optimization of the shape of the building) still do not give a very readable view of the degree of deviation, e.g. expressed in percentage points, relative to the reference solid. The introduction of a new indicator $\left(R C_{c d}\right)$ eliminates the need for an additional scale.

In addition, comparing to highly ideal solids (sphere, cube) and as a rule strongly differing from practical, functional shapes of buildings, especially detached houses, seems to be complicated and not revealing the essence of things. Meanwhile, the building designer would prefer to have relatively accurate simple indicators, best expressed in percentage points, giving deviations from the reference pattern, considered in terms of design, economy, ecology, etc. For example, by how many percentage points the surface area of the external walls of the building with the usable area design solution will be larger than the area of the optimal solution. It is connected with one-off construction costs and many operating costs (heating, maintenance, renovation).

Admittedly, Ourghi et al. (2007), Tuhus-Dubrow and Krarti (2010), Parasonis et al. (2012) propose using the relative compactness $(R C)$ coefficients, perfectly formulated and very well implemented, which express the ratio between the shape coefficient of a designed building and (differently defined) reference building, but this reference shape of building is not unified and requires complicated calculation software. Recent searches (Hemsath \& Bandhosseini, 2015; Rodrigues et al., 2015; Raof, 2017; Lim \& Kim, 2018) also do not bring simple proposals in this area. And the designers will use the building geometry indications if the proposals will be simple and will not hamper their creativity.

The authors of this paper have undertaken the task of looking for a more accurate and simple solution to this problem, so that the geometrical description of the object can be easily translated into energy costs, comfort of use as well as aesthetics. Therefore, they propose to introduce other, more realistic and intuitive, reference shapes. More general description parameters are introduced which al- low any reference solids (when defining compactness factors).

\section{Solid compactness indicators in the aspect of application for determining the compactness of building}

As we have already said, comparing the size of the surface area and volume ratio of the building body to the ratio of the same parameters for the cube has some imperfections. The building has a modular height within certain limits or a height equal to a multiple of the modular height (N. Neufert \& P. Neufert, 2012). It would be rational to compare it with a "cube-like" building, but with the same height (e.g. if the prism had a square base and the same height as the building under examination). If we assume that the solid has the structure of a straight prism, with the prism having the l-connected polygon as the basis (a classic polygon with polygonal holes), and the cylinder having any l-connected basis as the base, the standard solid may be a rectangular prism with a square base. The second disadvantage of compactness indicators introduced and used by Mahdavi and Gurtekin (2002) is the way of determining the ratio. The authors of this paper propose to replace the numerator with the denominator in Eqns (1), (2). Then the modified quotients will take values greater than (or equal to) one. After multiplying by $100 \%$, we get a result expressing the percentage increase in the surface area of the solid in relation to the area of the standard cube. We will get a readable indicator which is easy to interpret.

\subsection{Relative compactness indicator of a solid with respect to another solid}

First, we shall introduce a relative compactness indicator related to the arbitrarily adopted reference solid. As suggested, the parameters (more accurately the parameter of the total area) of the reference solid will be in the denominator of the fraction defining the indicator.

We assume that $R C_{\text {Spat }}$ (Relative compactness of solid $S$ with respect to reference solid $S_{p a t}$ ) is expressed as the quotient of the geometric compactness of the solid $S$ and the geometric compactness of the solid $\mathrm{S}_{\text {pat }}$

assuming that

$$
R C_{\text {Spat }}(\mathrm{S})=\frac{\frac{\mathrm{A}_{\mathrm{t}}(\mathrm{S})}{\mathrm{V}(\mathrm{S})}}{\frac{\mathrm{A}_{\mathrm{t}}\left(\mathrm{S}_{\mathrm{pat}}\right)}{\mathrm{V}\left(\mathrm{S}_{\mathrm{pat}}\right)}}\left(=\frac{\mathrm{A}_{\mathrm{t}}(\mathrm{S})}{\mathrm{A}_{\mathrm{t}}\left(\mathrm{S}_{\mathrm{pat}}\right)}\right) \text {, }
$$

$$
\mathrm{V}(\mathrm{S})=\mathrm{V}\left(\mathrm{S}_{\text {pat }}\right) \text {, }
$$

where $A_{t}(S)$ is the total area of the solid $S$.

$$
R C_{\text {cube }}=\frac{\mathrm{A}_{\mathrm{t}}(\mathrm{S})}{6 \sqrt[3]{\mathrm{V}(\mathrm{S})^{2}}},
$$

for any solid S.

Similarly we find the relative compactness indicator with respect to a sphere 


$$
R C_{\text {sphere }}=\frac{\mathrm{A}_{\mathrm{t}}(\mathrm{S})}{\sqrt[3]{36 \pi} 36 \sqrt[3]{\mathrm{V}(\mathrm{S})^{2}}} .
$$

Then we get the reversals of relationships known from the literature (Mahdavi \& Gurtekin, 2002):

$$
R C_{\text {cube }}=\left(R C_{\text {cube }}^{*}\right)^{-1},
$$

and

$$
R C_{\text {sphere }}=\left(R C_{\text {sphere }}^{*}\right)^{-1} .
$$

\subsection{Relative compactness indicator with respect to a cuboid}

Let $\mathrm{S}$ now be a prism on base $\mathrm{B}$ and height $h$. Let $\mathrm{A}_{\mathrm{b}}(\mathrm{B})$ denote the area of the base $B$ and $\mathrm{P}_{b}(\mathrm{~B})$ the perimeter of the base $B$. Let us assume that $S_{\text {pat }}$ is a cuboid (a rectangular prism with a base of a square) with an edge length $a$ and a height $h$. Using (3), we will define the relative compactness of a solid $\mathrm{S}$ with respect to a cuboid

$$
R C_{c d}=R C_{\text {Spat }}(\mathrm{S})
$$

Because $\mathrm{V}(\mathrm{S})=\mathrm{A}_{\mathrm{b}}(\mathrm{B}) h$ due to (4) we have $\mathrm{A}_{\mathrm{b}}(\mathrm{B}) h=a^{2} h$, hence $\mathrm{A}_{\mathrm{b}}(\mathrm{B})=a^{2}$. Then $a=\sqrt{\mathrm{A}_{\mathrm{b}}(\mathrm{B})}$. Therefore $\mathrm{A}_{\mathrm{t}}(\mathrm{S})=$ $2 \mathrm{~A}_{\mathrm{b}}(\mathrm{B})+\mathrm{P}_{\mathrm{b}}(\mathrm{B}) h$. Simultaneously $\mathrm{A}_{\mathrm{t}}\left(\mathrm{S}_{\mathrm{pat}}\right)=2 a^{2}+4 a h$. Due to $a=\sqrt{\mathrm{A}_{\mathrm{b}}(\mathrm{B})}$ we get $\mathrm{A}_{\mathrm{t}}\left(\mathrm{S}_{\mathrm{pat}}\right)=2 \mathrm{~A}_{\mathrm{b}}(\mathrm{B})+4 \sqrt{\mathrm{A}_{\mathrm{b}}(\mathrm{B})}$ $h$. After substituting into the Eqn (3) we get

$$
R C_{c d}=\frac{2 \mathrm{~A}_{\mathrm{b}}(\mathrm{B})+\mathrm{P}_{\mathrm{b}}(\mathrm{B}) h}{2 \mathrm{~A}_{\mathrm{b}}(\mathrm{B})+4 \sqrt{\mathrm{A}_{\mathrm{b}}(\mathrm{B})} h} .
$$

\subsection{Relative compactness indicator with respect to a square}

One can give up the height of the prism and the surface of the top and bottom bases of the solids. The reference will be only the shape of the solid's base $B$. Let $P_{b}(B)$ be the perimeter and $A_{b}(B)$ area of a planar figure $B$. Then relative compactness indicator of figure $B$ with respect to the square has a form

$$
R C_{s q}\left(=\frac{\frac{\mathrm{P}_{\mathrm{b}}(\mathrm{B})}{\mathrm{A}_{\mathrm{b}}(\mathrm{B})}}{\frac{4}{\sqrt{\mathrm{A}_{\mathrm{b}}(\mathrm{B})}}}\right)=\frac{\mathrm{P}_{\mathrm{b}}(\mathrm{B})}{4 \sqrt{\mathrm{A}_{\mathrm{b}}(\mathrm{B})}} .
$$

The Eqn (10) can be recognized as the relative compactness of the prism $G$ with the base $B$ (and omitted in the consideration of the height $h$ ), referred to the cuboid with a square base with area equal to the base B of the prism $\mathrm{G}$ (and omitted in the consideration of the height $h$ ).

Now let's transform the Eqn (10) and calculate the limit with $h \rightarrow \infty$ :

$$
\lim _{h \rightarrow \infty} \frac{\frac{2 \mathrm{~A}_{\mathrm{b}}(\mathrm{B})}{h}+\mathrm{P}_{\mathrm{b}}(\mathrm{B})}{\frac{2 \mathrm{~A}_{\mathrm{b}}(\mathrm{B})}{h}+4 \sqrt{\mathrm{A}_{\mathrm{b}}(\mathrm{B})}}=\frac{\mathrm{P}_{\mathrm{b}}(\mathrm{B})}{4 \sqrt{\mathrm{A}_{\mathrm{b}}(\mathrm{B})}},
$$

i.e. $\lim _{h \rightarrow \infty} R C_{c d}=R C_{s q}$.
So we have a situation in which it can be concluded that the $R C_{s q}$ indicator is the effective assessment of the compactness of a high building. Anyway, the result is intuitively easy to verify. Namely, a high building with an optimal compactness will have a square-like contour. It would seem that the omission of height in evaluating the compactness of the building, the property of merely highrise buildings, or rather very high. A closer analysis allows noticing that the height of a building is actually a matter of recognition of the investor and designer. In the case of a residential building in Poland, this is the size specified by law (Decree of the Minister of Infrastructure and Development, 2015), in the case of buildings for special purposes (industrial and sports halls) the height of the storey also remains outside the rational actions of the optimization analyses. The height of the building is naturally excluded from the assessment of its compactness. So we have two options when determining the compactness of a building: (A) arbitrarily take the height $h$ of the building (storeys) and then the indicator of compactness $R C_{c d}$ is the best measure of compactness or (B) omit the height when determining the compactness of the building and then the best indicator of the compactness of the building is the indicator $R C_{s q}$. Of course, this does not mean failing to take into account the height of the building in the calculations. The side surface of the building body will be determined by multiplying the perimeter of the contour (base polygon) by the height of the object, we will determine the floor surface (ceiling) directly by calculating the area of the contour (base polygon). Hence, the main parameter of the shape of a building is its plan. For this reason, we will discuss the so-called defect perimeter of the polygon, then generalize it for any figure (Koźniewski, 2015).

\subsection{Rectangular polygons inscribed in rectangle. How to specify a reference building?}

The vast majority of single-family houses and buildings in general is designed on a rectangular polygon plan (Koźniewski, 2007, 2015). The introduced coefficients $R C_{c d}$ and $R C_{s q}$ do not exhaust the parameters characterizing the shape of the building on the plan described by a polygon with right angles, but more complex than a rectangle. It is necessary to determine natural indicators describing the properties of the so-called rectangular polygon. A rectangular polygon (Figures 4,5 ) is a polygon that has only right convex angles (90 degrees) and concave angles (270 degrees). The polygon has always an even number of sides (Koźniewski, 2007) and the difference between the number of convex and concave angles is equal to 4 (Koźniewski, 2007, 2015). Each two sides of the rectangular polygon are parallel or perpendicular to each other. For each polygon of this type, there is exactly one rectangle circumscribed on it. Let's assume that a rectangular polygon $R_{P}$ and a rectangle $R$ (circumscribed on it) are given. 

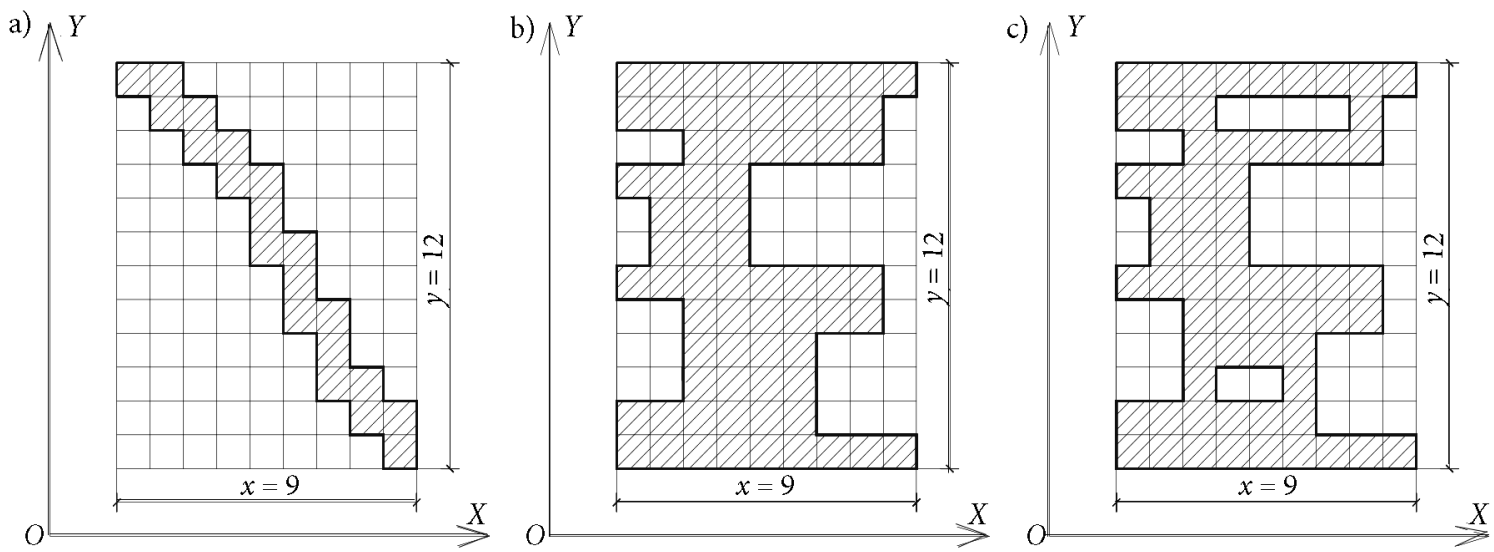

Figure 2. Rectangular polygons (hatched) inscribed in a rectangle with dimensions of $x \times y, x=9 u, y=12 u$ :

a) with a big area defect $\left(\triangle \mathrm{Ab}=88 u^{2}\right), R D A=0.81(81 \%)$, and zero's perimeter defect, $R D P=0(0 \%)$;

b) with a positive perimeter defect $(\triangle \mathrm{Pb}=24 u, R D P=0.57(57 \%))$, with area defect $\left(\triangle \mathrm{Ab}=38 u^{2}\right.$, $R D A=0.35(35 \%)) ; \mathrm{c})$ with a positive perimeter defect $(\Delta \mathrm{Pb}=40 u, R D P=0.95(95 \%))$, with area defect $\left(\triangle \mathrm{Ab}=44 u^{2}, R D A=0.41(41 \%)\right)$

\subsubsection{Perimeter defect and area defect}

Let us denote the perimeter (area) of the rectangular polygon $\mathrm{R}_{\mathrm{P}}$ and the rectangle by $\mathrm{P}_{\mathrm{b}}(\mathrm{R})\left(\mathrm{P}_{\mathrm{b}}\left(\mathrm{R}_{\mathrm{P}}\right)\right), \mathrm{A}_{\mathrm{b}}(\mathrm{R})$ $\left(A_{b}(R P)\right)$, respectively. The following number of $\Delta P_{b}\left(R_{P}\right)$ $\left(\Delta A_{b}\left(R_{P}\right)\right)$ is expressed as follows:

$$
\begin{aligned}
& \Delta \mathrm{P}_{\mathrm{b}}\left(\mathrm{R}_{\mathrm{P}}\right)=\mathrm{P}_{\mathrm{b}}\left(\mathrm{R}_{\mathrm{P}}\right)-\mathrm{P}_{\mathrm{b}}(\mathrm{R}), \\
& \Delta \mathrm{A}_{\mathrm{b}}\left(\mathrm{R}_{\mathrm{P}}\right)=\mathrm{A}_{\mathrm{b}}(\mathrm{R})-\mathrm{A}_{\mathrm{b}}\left(\mathrm{R}_{\mathrm{P}}\right),
\end{aligned}
$$

and called the perimeter defect (area defect) of the rectangular polygon $\mathrm{R}_{\mathrm{P}}$ (Koźniewski, 2015) (Figure 2).

Perimeter defect and area defect of the polygon defined in absolute terms do not reflect the size of the measurement deviations from perimeter and area of a rectangle. Besides, in practical applications these will depend on the accepted measurement units of length and area. Therefore, it is desirable to describe these measurement deviations (from the ideal figure - a rectangle) in a relative manner.
Let us introduce therefore, two concepts: the relative defect of perimeter of the rectangular polygon

$$
R D P\left(\mathrm{R}_{\mathrm{P}}\right)=\frac{\Delta \mathrm{P}_{\mathrm{b}}\left(\mathrm{R}_{\mathrm{P}}\right)}{\mathrm{P}_{\mathrm{b}}(\mathrm{R})},
$$

and the relative defect of area of the rectangular polygon

$$
R D A\left(\mathrm{R}_{\mathrm{P}}\right)=\frac{\Delta \mathrm{A}_{\mathrm{b}}\left(\mathrm{R}_{\mathrm{P}}\right)}{\mathrm{A}_{\mathrm{b}}(\mathrm{R})} .
$$

Relative defect of area, with the defect of perimeter equal to zero, shows the degree of "imperfections" of the border line. The same length of perimeter takes up roughly $\frac{\Delta A_{b}\left(R_{P}\right)}{A_{b}(R)} \times 100 \%$ smaller area; so there is loss in the area at the same perimeter. Because the larger the perimeter defect the larger perimeter, area defect with increased perimeter results in even greater losses of the area.

Let us assume the following shape of a rectangular polygon (Figure 3(b)) and the rectangle described on it

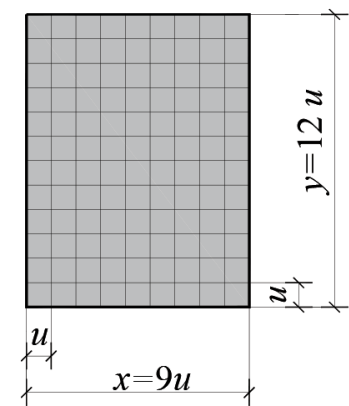

$$
\begin{aligned}
& \mathrm{A}_{\mathrm{b}}=108 u^{2} \\
& \mathrm{P}_{\mathrm{b}}=42 u
\end{aligned}
$$

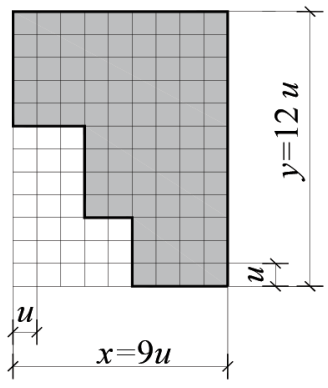

$$
\begin{array}{ll}
\mathrm{A}_{\mathrm{b}}=81 u^{2} & R D A_{\mathrm{R}}=0.25 \\
\mathrm{P}_{\mathrm{b}}=42 u & R D P=0 \\
& R D A^{\prime}=0.33
\end{array}
$$

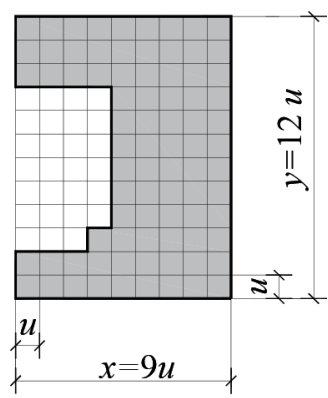

$$
\begin{array}{ll}
\mathrm{A}_{\mathrm{b}}=81 u^{2} & R D A_{\mathrm{R}}=0.25 \\
\mathrm{P}_{\mathrm{b}}=50 u & R D P=8 / 42=0.19 \\
& R D A^{\prime}=0.33
\end{array}
$$

(c) (c)

(a)

(b)

Figure 3. The base rectangle and a rectangular polygon inscribed therein: (a) reference rectangle; (b) rectangular polygon with a perimeter defect equal to zero; (c) rectangular polygon with a perimeter defect different from zero 
(Figure 3(a)), which we will treat as a reference rectangle. The values of areas and perimeters are: $A_{b}(R)=108 u^{2}$, $\mathrm{A}_{\mathrm{b}}\left(\mathrm{R}_{\mathrm{P}}\right)=81 u^{2}, \mathrm{P}_{\mathrm{b}}(\mathrm{R})=42 u, \mathrm{P}_{\mathrm{b}}\left(\mathrm{R}_{\mathrm{P}}\right)=42 u$. Due to (17) we have $R D A\left(\mathrm{R}_{\mathrm{P}}\right)=27 / 108$. We can say that the area defect is $25 \%$. This defect is measured relative to the rectangle described on the rectangular polygon and referenced to this rectangle. Another reference may be used and in the Eqn (17) we can write $A_{b}\left(R_{p}\right)$ instead of $A_{b}(R)$. Then we obtain

$$
R D A^{\prime}\left(\mathrm{R}_{\mathrm{P}}\right)=\frac{\Delta \mathrm{A}_{\mathrm{b}}\left(\mathrm{R}_{\mathrm{P}}\right)}{\mathrm{A}_{\mathrm{b}}\left(\mathrm{R}_{\mathrm{P}}\right)} .
$$

Indicators $R D A$ and $R D A$ ' are dependent on each other, namely $R D A^{\prime}=\frac{R D A}{1-R D A}$. Then, for the data presented in Figure $3(\mathrm{~b})$, we will have $R D A^{\prime}\left(\mathrm{R}_{\mathrm{P}}\right)=\frac{27}{81}$. Then the relative area defect will be $33 \%$.

In the example described in Figure 3(b), the perimeters of comparable figures were the same. Let's take another example (Figure 3(c)). The perimeters of the figures are different, so it is advisable to use a different indicator. In the second case perimeter defect equals 8 , so the relative defect of perimeter $R D P\left(\mathrm{R}_{\mathrm{P}}\right)=8 / 42$. Thus the relative defect of perimeter is $19 \%$. In relation to the rectangle described on the discussed rectangular polygons (Figures 3(b), 3(c)), defects are $0 \%$ and $19 \%$ respectively with the same relative area error $R D A=0.25$ relative to the rectangle or the same relative field defect $R D A^{\prime}=0.33$ in relation to a rectangular polygon. Summing up, we can say that the RDA informs us how much space (and cubage) we have lost by giving up the rectangle as the contour of the building contour while maintaining a given surface of external partition walls (if $R D P>0$ ). Whereas $R D A^{\prime}$ informs us how much surface of the external partition walls $(R D P=0)$ or how much space (and cubic capacity) we could gain by changing the surface of the external partitions by $R D P$ (if $R D P>0$ ).

\subsubsection{Proposal for definition of a reference building}

Let us generalize a perimeter defect by referring to a given figure (rectangular polygon $\mathrm{R}_{\mathrm{P}}$ or even any figure $\mathrm{F}$ with area $A(F)$ ) to a figure with the same area being a reference rectangle $\mathrm{R}_{k}$ with a ratio of sides equal to $k$. Then $\mathrm{R}_{1}$ $(k=1)$ is a square, $\mathrm{R}_{1+\sqrt{2}}(k=1+\sqrt{2})$ (with the different designation $R_{s}$ ) is a rectangle with the silver side ratio, used in architecture $\mathrm{R}_{\frac{1+\sqrt{5}}{2}}\left(k=\frac{1+\sqrt{5}}{2}\right)$ with the different designation $\mathrm{R}_{\mathrm{g}}$ a rectangle with the golden side ratio, $\mathrm{R}_{2}(k=2)$ is a rectangle used in architecture (N. Neufert \& $\mathrm{P}$. Neufert, 2012), $\mathrm{R}_{\frac{4}{3}}\left(k=\frac{4}{3}\right)$ is a rectangle with the dimensions adopted in Figure 3(a). The area of the rectangle $\mathrm{R}_{k}$ (with the ratio of one side to the other side shorter or equal) can be written in the form

$$
\mathrm{A}_{\mathrm{b}}\left(\mathrm{R}_{\mathrm{k}}\right)=k r^{2} \text {, }
$$

where $r$ is the length of the shorter side $(1 \leq k)$. Assume that the areas of the rectangle $\mathrm{R}_{k}$ and figure $\mathrm{F}$ are equal. Then

$$
\mathrm{A}_{\mathrm{b}}(\mathrm{F})=k r^{2} .
$$

Hence

$$
r=\sqrt{\frac{\mathrm{A}_{\mathrm{b}}(\mathrm{F})}{k}} .
$$

Then the perimeter of the reference rectangle $\mathrm{R}_{k}$ for the given figure $\mathrm{F}$ is

$$
\mathrm{P}_{\mathrm{b}}\left(\mathrm{R}_{\mathrm{k}}\right)=2 r(1+k)=2 \sqrt{\frac{\mathrm{A}_{\mathrm{b}}(\mathrm{F})}{k}}(1+k) .
$$

The perimeter defect and the relative defect of perimeter are correspondingly equal

$$
\Delta \mathrm{P}_{\mathrm{b}}(\mathrm{F})=\mathrm{P}_{\mathrm{b}}(\mathrm{F})-2 \sqrt{\frac{\mathrm{A}_{\mathrm{b}}(\mathrm{F})}{k}}(1+k)
$$

Table 4. List of relative defects of perimeter depending on the ratio of sides $k$ of rectangles

\begin{tabular}{|l|c|c|}
\hline \multicolumn{1}{|c|}{ Name } & Ratio of sides $k$ & Formula \\
\hline $\begin{array}{l}\text { Relative defect of perimeter per } \\
\text { rectangle with a side ratio 4:3 }\end{array}$ & $k=\frac{4}{3}$ & $R D P_{4: 3}(\mathrm{~F})=\frac{\mathrm{P}_{\mathrm{b}}(\mathrm{F})-\frac{7}{3} \sqrt{3 \mathrm{~A}_{\mathrm{b}}(\mathrm{F})}}{\frac{7}{3} \sqrt{3 \mathrm{~A}_{\mathrm{b}}(\mathrm{F})}}$ \\
\hline $\begin{array}{l}\text { Relative defect of perimeter per "silver" } \\
\text { rectangle }\end{array}$ & $k=1+\sqrt{2}$ & $R D P_{\mathrm{s}}(\mathrm{F})=\frac{\mathrm{P}_{\mathrm{b}}(\mathrm{F})-2 \sqrt{\mathrm{A}_{\mathrm{b}}(\mathrm{F})(\sqrt{2}-1)(2+\sqrt{2})}}{2 \sqrt{\mathrm{A}_{\mathrm{b}}(\mathrm{F})(\sqrt{2}-1)(2+\sqrt{2})}}$ \\
\hline $\begin{array}{l}\text { Relative defect of perimeter per "golden" } \\
\text { rectangle }\end{array}$ & $k=\frac{1+\sqrt{5}}{2}$ & $R D P_{\mathrm{g}}(\mathrm{F})=\frac{\mathrm{P}_{\mathrm{b}}(\mathrm{F})-\sqrt{\frac{\left.\mathrm{A}_{\mathrm{b}}(\mathrm{F}) \sqrt{5}-1\right)}{2}(3+\sqrt{5})}}{\sqrt{\frac{\left.\mathrm{A}_{\mathrm{b}}(\mathrm{F}) \sqrt{5}-1\right)}{2}(3+\sqrt{5})}}$ \\
\hline $\begin{array}{l}\text { Relative defect of perimeter per } \\
\text { rectangle with a side ratio } 2: 1\end{array}$ & $k=2$ & $R D P_{2}(\mathrm{~F})=\frac{\mathrm{P}_{\mathrm{b}}(\mathrm{F})-6 \sqrt{\frac{\mathrm{A}_{\mathrm{b}}(\mathrm{F})}{2}}}{6 \sqrt{\frac{\left.\mathrm{A}_{\mathrm{b}} \mathrm{F}\right)}{2}}}$ \\
\hline
\end{tabular}




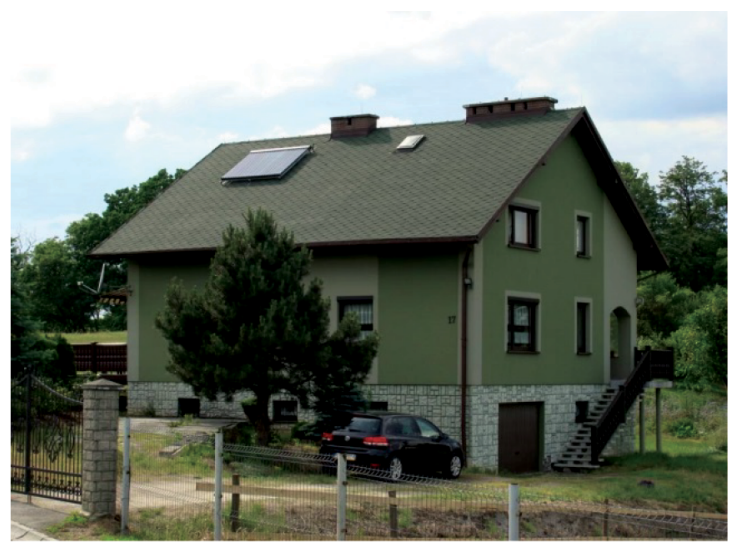

Characteristics of the building's shape

Plan: rectangular polygon

Roof: gable roof (with eaves)

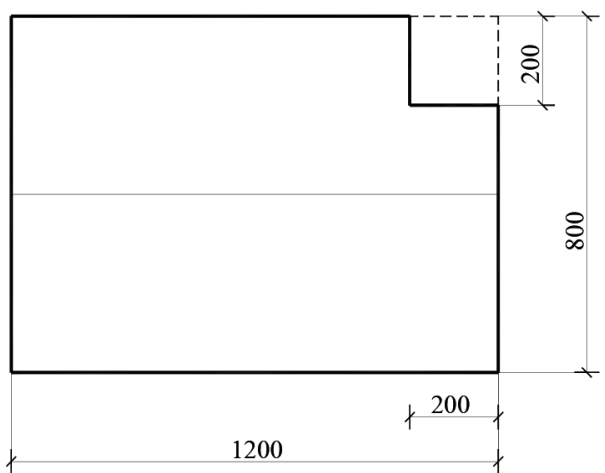

Compactness indicators of the building

$\begin{array}{ll}h=270[\mathrm{~cm}] & \Delta \mathrm{P}_{\mathrm{b}}(\ldots)=0 \\ R C_{\text {cube }}=1.22 & R C_{c d}=1.02 \\ R D A=0.04 & R D P_{1}=0.04\end{array}$

Figure 4. Characteristics of the shape of an existing building and its selected indicators of compactness

$$
R D P_{k}(\mathrm{~F})=\frac{\mathrm{P}_{\mathrm{b}}(\mathrm{F})-2 \sqrt{\frac{\mathrm{A}_{\mathrm{b}}(\mathrm{F})}{k}}(1+k)}{2 \sqrt{\frac{\mathrm{A}_{\mathrm{b}}(\mathrm{F})}{k}}(1+k)} .
$$

List of relative defects of perimeter is provided in Table 4 .

Assuming in Eqn (24) $k=1$ we obtain a relative defect of perimeter related to the square

$$
R D P_{1}(\mathrm{~F})=\frac{\mathrm{P}_{\mathrm{b}}(\mathrm{F})-4 \sqrt{\mathrm{A}_{\mathrm{b}}(\mathrm{F})}}{4 \sqrt{\mathrm{A}_{\mathrm{b}}(\mathrm{F})}} .
$$

A comparison of Eqns (11) and (25) allows noting of their relationship. Indeed, after replacing in the Eqn (25) the variable $\mathrm{F}$ by $\mathrm{B}$ we get

$$
R D P_{1}(\mathrm{~B})=\mathrm{RC}_{\mathrm{sq}}(\mathrm{B})-1 \text {. }
$$

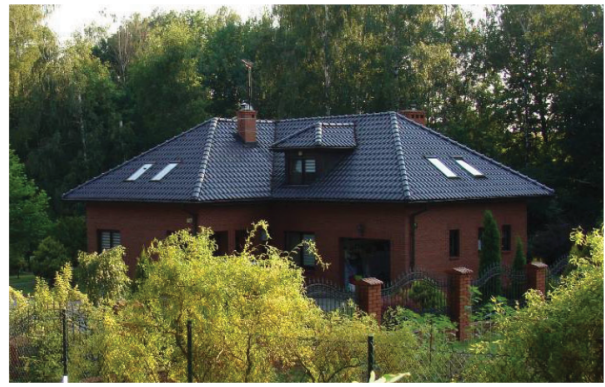

Characteristics of the building's shape

\section{Compactness indicators of existing or designed buildings}

The test of indicators formulated and described in the paper was carried out in two groups of buildings: existing spotted locally and those whose designs can be found in the selected catalog available on the website.

\subsection{Compactness indicators of existing buildings}

Field research was carried out in Jastrzębie Zdrój (Poland). Six buildings have been analyzed. On the basis of dimensions (from the inventory), the roof skeleton has been reconstructed and the values of the indicators $R C_{c u b e}$, $R C_{c d}, R D A$ and $R D P_{1}$ were calculated (Figures 4, 5 and 6). Garages that are usually not heated are not included in the calculation of indicators.

The values of indicators for all randomly selected six examined existing buildings are shown in Table 5 . The val-

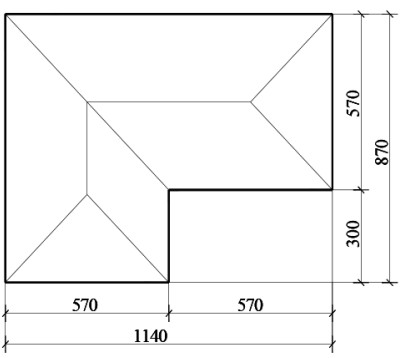

Compactness indicators of the building

Plan: rectangular polygon

$$
\begin{array}{ll}
h=270[\mathrm{~cm}] & \Delta \mathrm{P}_{\mathrm{b}}(\ldots)=0 \\
R C_{\text {cube }}=1.23 & R C_{c d}=1.04
\end{array}
$$

of them, a dormer covered with a three-sided roof

$$
R D A=0.17
$$$$
R D P_{1}=0.11
$$ 


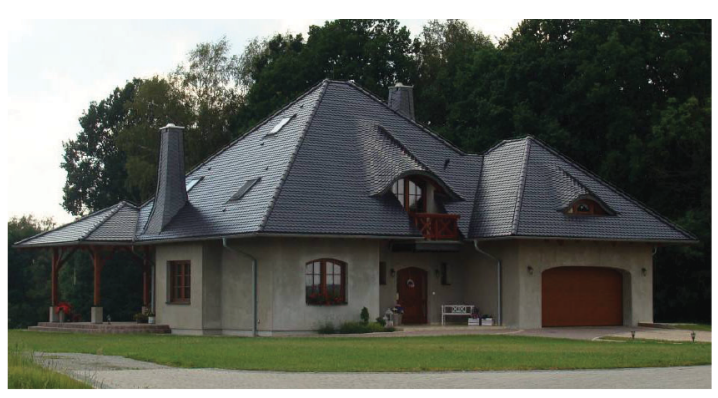

Characteristics of the building's shape

Plan: rectangular polygon

Roof: composed equally of three four-sloped roofs; in two of them, dormers covered with a curvilinear surfaces

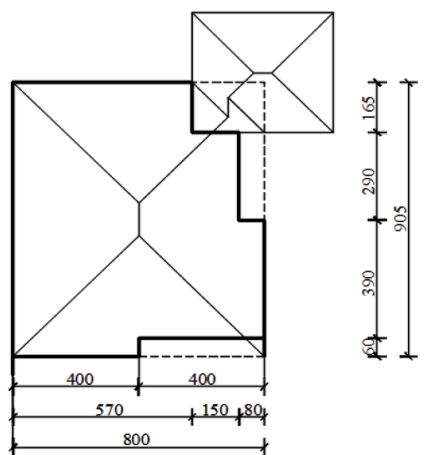

Compactness indicators of the building

$R D A=0.12$

$R D P_{1}=0.07$

Figure 6. Characteristics of the shape of an existing building and its selected indicators of compactness
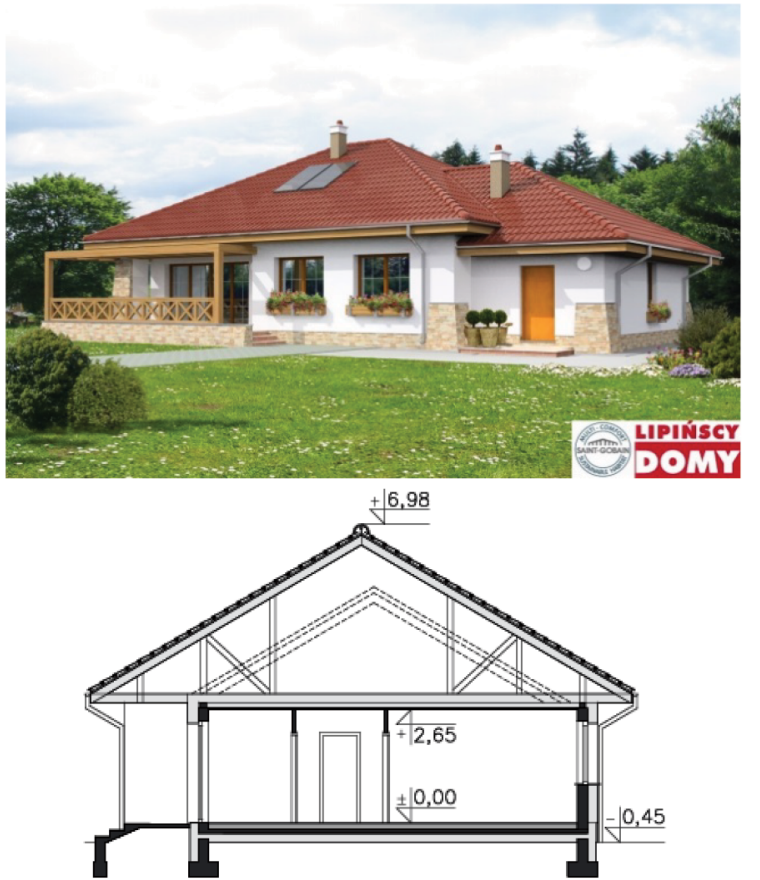

Characteristics of the building's shape

Plan: rectangular polygon

Roof: composed subordinately of two roofs: a four-sloped roof and a three-sloped roof
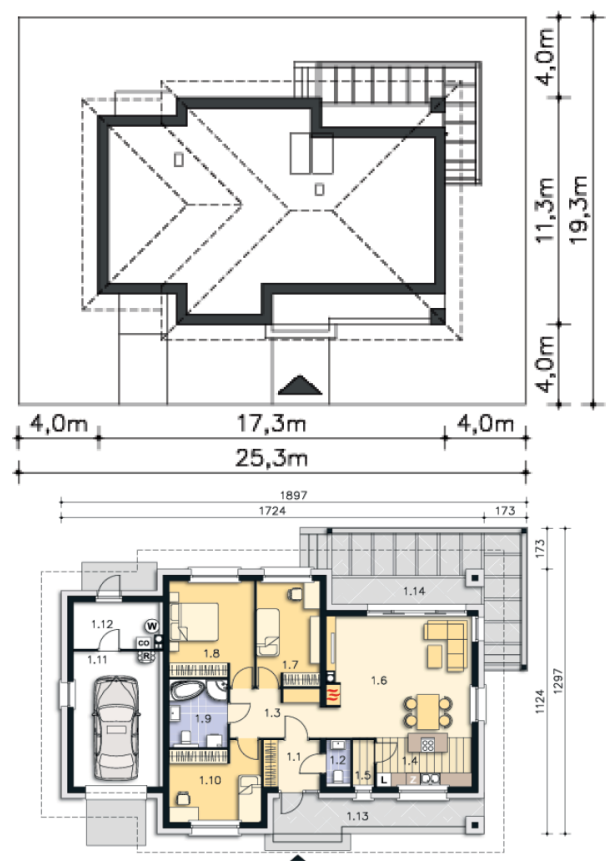

Compactness indicators of the building

$$
\begin{array}{ll}
h=261[\mathrm{~cm}] & \Delta \mathrm{P}_{\mathrm{b}}(\ldots)=0 \\
R C_{\text {cube }}=1.29 & R C_{c d}=1.03 \\
R D A=0.15 & R D P_{1}=0.09
\end{array}
$$

Figure 7. Characteristics of the shape of an existing building and its selected compactness indicators on the basis of the design Denver DCB112 MC. In the calculation, a garage that is not heated is not included. The design was downloaded from Lipinscy Domi (2018)

ue of the $R C_{\text {cube }}$ indicator is much higher than 1 , which indicates a significant deviation of the shape of the building from the model cube. It ranges from $17 \%$ to $27 \%$. The values of the indicators $R C_{c d}$ behave differently. They indi- cate small differences in shapes compared to the standard shape. Let us remind you that this shape is a rectangular prism with a square base (i.e. cuboid) and a height equal to the height of the building under examination. 
Table 5. Parameters of the examined existing buildings

\begin{tabular}{|c|c|c|c|c|c|c|}
\hline & $h[\mathrm{~cm}]$ & $\Delta \mathrm{P}_{\mathrm{b}}(\ldots)[\mathrm{cm}]$ & $R C_{\text {cube }}$ & $R C_{c d}$ & $R D A$ & $R D P_{1}$ \\
\hline 1 & 270 & 0 & 1.22 & 1.02 & 0.04 & 0.04 \\
\hline 2 & 270 & 250 & 1.27 & 1.04 & 0.05 & 0.10 \\
\hline 3 & 270 & 0 & 1.23 & 1.04 & 0.17 & 0.11 \\
\hline 4 & 270 & 0 & 1.23 & 1.03 & 0.15 & 0.09 \\
\hline 5 & 270 & 0 & 1.20 & 1.02 & 0.10 & 0.06 \\
\hline 6 & 270 & 0 & 1.17 & 1.03 & 0.12 & 0.07 \\
\hline
\end{tabular}
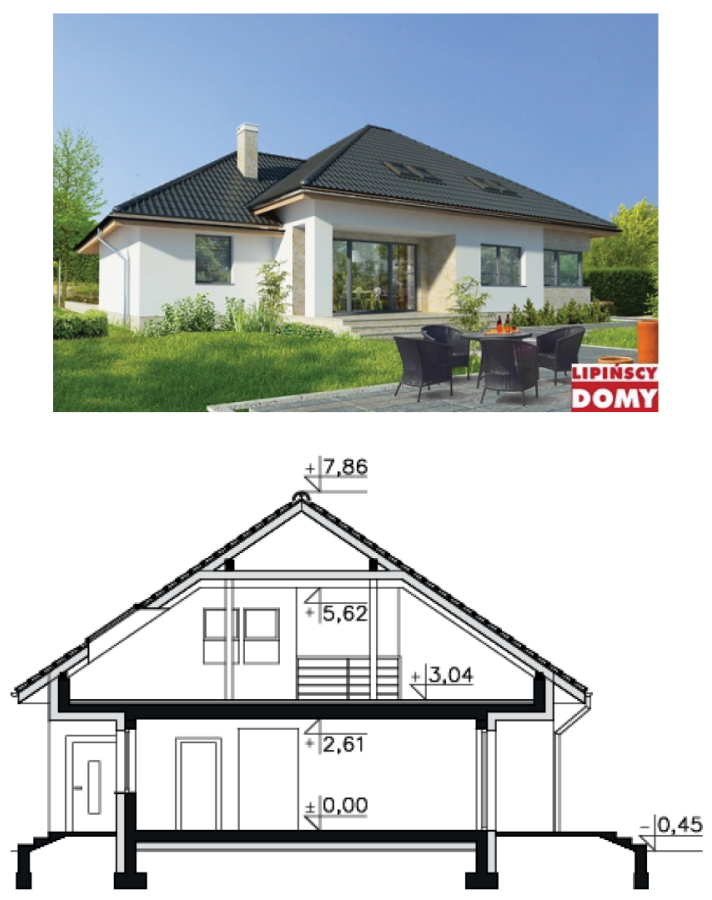

Characteristics of the building's shape

Plan: rectangular polygon

Roof: composed subordinately of two roofs: a four-sloped roof and a three-sloped roof
Table 6. Parameters of the six examined buildings, calculated on the basis of the dimensions of the building design

\begin{tabular}{|c|c|c|c|c|c|c|}
\hline & $h[\mathrm{~cm}]$ & $\Delta \mathrm{P}_{\mathrm{b}}(\ldots)[\mathrm{cm}]$ & $R C_{\text {cube }}$ & $R C_{c d}$ & $R D A$ & $R D P_{1}$ \\
\hline 1 & 265 & 0 & 1.29 & 1.03 & 0.15 & 0.09 \\
\hline 2 & 261 & 0 & 1.30 & 1.02 & 0.11 & 0.06 \\
\hline 3 & 261 & 300 & 1.27 & 1.02 & 0.10 & 0.06 \\
\hline 4 & 263 & 0 & 1.21 & 1.00 & 0.00 & 0.00 \\
\hline 5 & 265 & 0 & 1.24 & 1.02 & 0.10 & 0.06 \\
\hline 6 & 284 & 0 & 1.25 & 1.01 & 0.05 & 0.03 \\
\hline
\end{tabular}

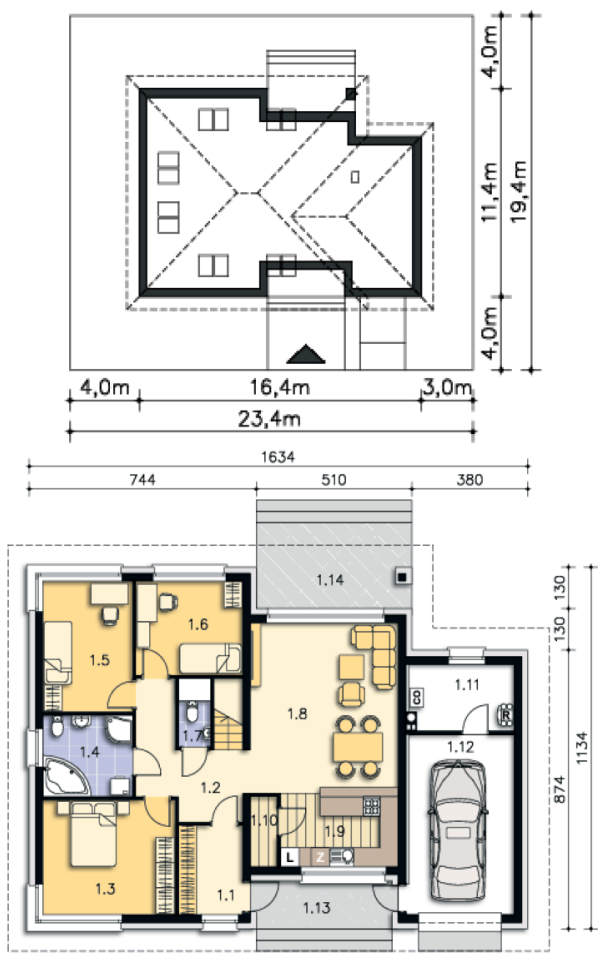

Compactness indicators of the building

$$
\begin{array}{cc}
h=261[\mathrm{~cm}] & \Delta \mathrm{P}_{\mathrm{b}}(\ldots)=300[\mathrm{~cm}] \\
R C_{\text {cube }}=1.27 & R C_{c d}=1.02 \\
R D A=0.10 & R D P_{1}=0.06
\end{array}
$$

Figure 8. Characteristics of the shape of an existing building and its selected compactness indicators on the basis of the design Bastia DCB111. In the calculation, a garage that is not heated is not included. The design was downloaded from Lipinscy Domi (2018)

\subsection{Compactness indicators of designed buildings}

The analysis of buildings in the design phase was made on the basis of information posted on the website. On the basis of dimensions, the values of indicators $R C_{\text {cube }}, R C_{c d}$, $R D A$ and $R D P_{1}$ were calculated (Figures 7, 8 and 9). In all the cases, the $R C_{\text {cube }}$ indicator indicates quite a large deviation from the ideal cubical shape $(1.29,1.27,1.21$, or $29 \%, 27 \%$ and $21 \%$, respectively). The $R C_{c d}$ indicator values showing the deviations from the square-shaped cuboid shape are $1.03 ; 1.02 ; 1.00$, or $3 \%, 2 \%, 0 \%$. However, the last indicator determines the ideal shape of the building, coinciding with the reference shape. It is worth noting that this house was designed as a passive, energysaving building. The values of $R D A$ and $R D P_{1}$ are equally interesting - both equal to zero. It is worth noting that there are buildings with real shapes and dimensions with the $R C_{c d}=1$ indicator value (Figure 9), while there are no buildings with real dimensions, with the $R C_{\text {cube }}=1$.

\subsection{Indicators for research models of building solids}

In addition to the compactness ratios calculated for existing and designed buildings, an analysis of the size of the indicators for the adopted 48 building research models 

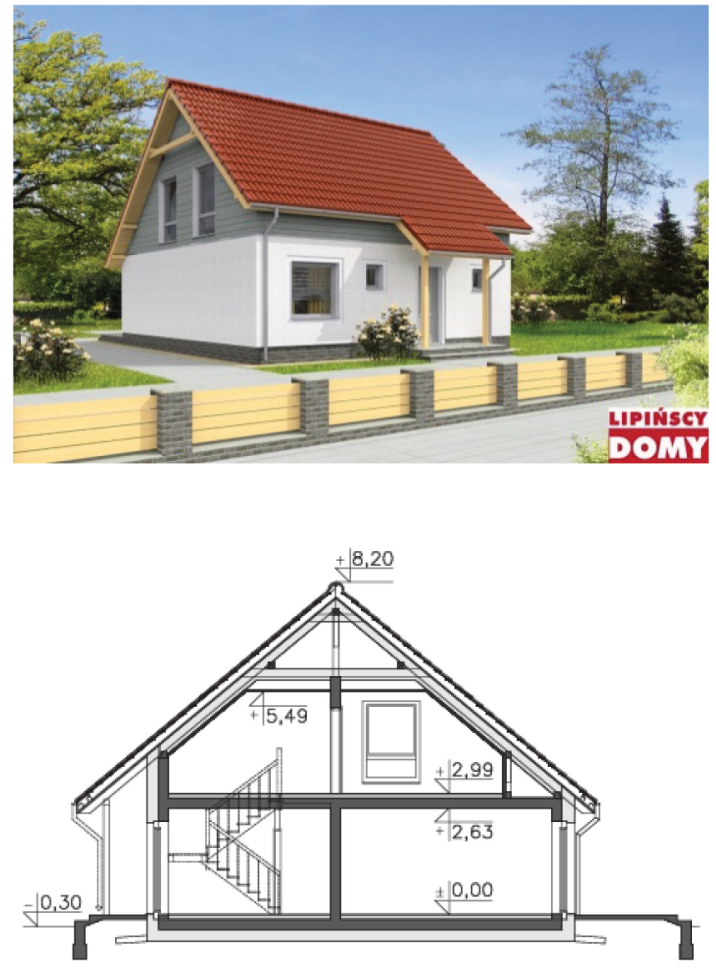

Characteristics of the building's shape

Plan: rectangular polygon

Roof: gable with reduction of one of the roof's surfaces

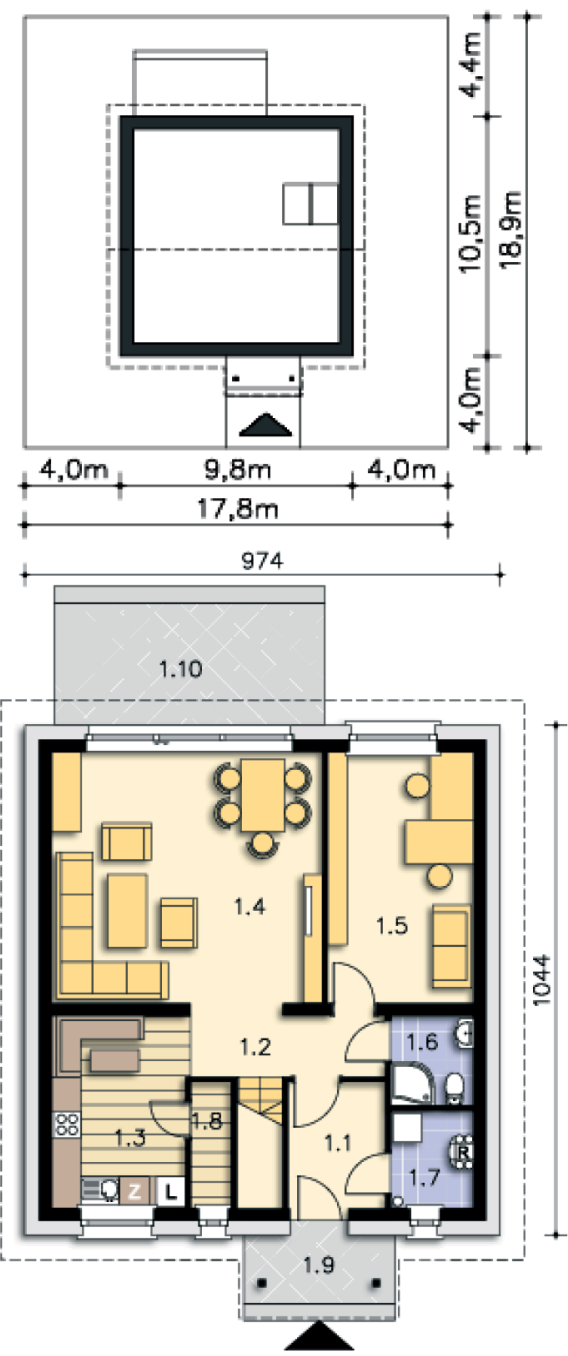

Compactness indicators of the building

$$
\begin{array}{ll}
h=263[\mathrm{~cm}] & \Delta \mathrm{P}_{\mathrm{b}}(\ldots)=0 \\
R C_{\text {cube }}=1.21 & R C_{c d}=1.00 \\
R D A=0.00 & R D P_{1}=0.00
\end{array}
$$

Figure 9. Characteristics of the shape of an existing building and its selected compactness indicators on the basis of the design Valletta Pasywny LDP06. The design was downloaded from Lipinscy Domi (2018)

was made, which is shown in Figure 10. The study of the compactness of buildings was carried out on the basis of a catalog of finished projects (Projekty Muratordom, 2018). At the beginning, it should be emphasized that the correlation coefficient calculated between the $R C_{\text {cube }}$ and $R C_{c d}$ index values for 48 building models is equal to 0,7876 (for the first 10 models it is 0.8614 , for the first 22 models it is equal to 0.8748 , and for the first 30 models it equals $0.8733)$. In this sense, the $R C_{c d}$ indicator is a generalization $R C_{\text {cube }}$ and the $R C_{\text {cube }}$ indicator can be replaced by $R C_{c d}$. Interestingly, the $R C_{c d}$ index is lower, but the graph of this indicator is more flattened than $R C_{c u b e}$. Less sensitivity to changes is complemented by $R C_{s q}$ values that give greater variability between individual models. Both $R C_{c d}$ and $R C_{s q}$ indicators simultaneously present a more accurate variation of the compactness of the objects. We will see a more complete image of the relationship by analyzing the values of the other indicators: $R D P, R D A$, $R D A^{\prime}$ and $R D P_{1}$ (Figure 11). We have $R D P=0$ in more than half of the research building models. All buildings have $R D A>0$. For building No. 48 , the $R D A$ indicator is as much as $40 \%$, and the $R D A^{\prime}$ is almost $70 \%$ (Figure 12 ). We will see a more complete image of the relationship by analyzing the values of the other indicators: $R D P, R D A$, $R D A^{\prime}$ and $R D P_{1}$ (Figure 11). We have $R D P=0$ in more than half of the research building models. These indicators are dictated by, among others, that the designer wanted the building span to not exceed $10 \mathrm{~m}$. This span is exactly $9.8 \mathrm{~m}$. Because the $R D P>0$ building material used for the exterior walls of building No. 48 would be enough for a rectangular building with dimensions of $21.3 \times 22.9$ [m]. But then the span of the building would be $21.3 \mathrm{~m}$. 


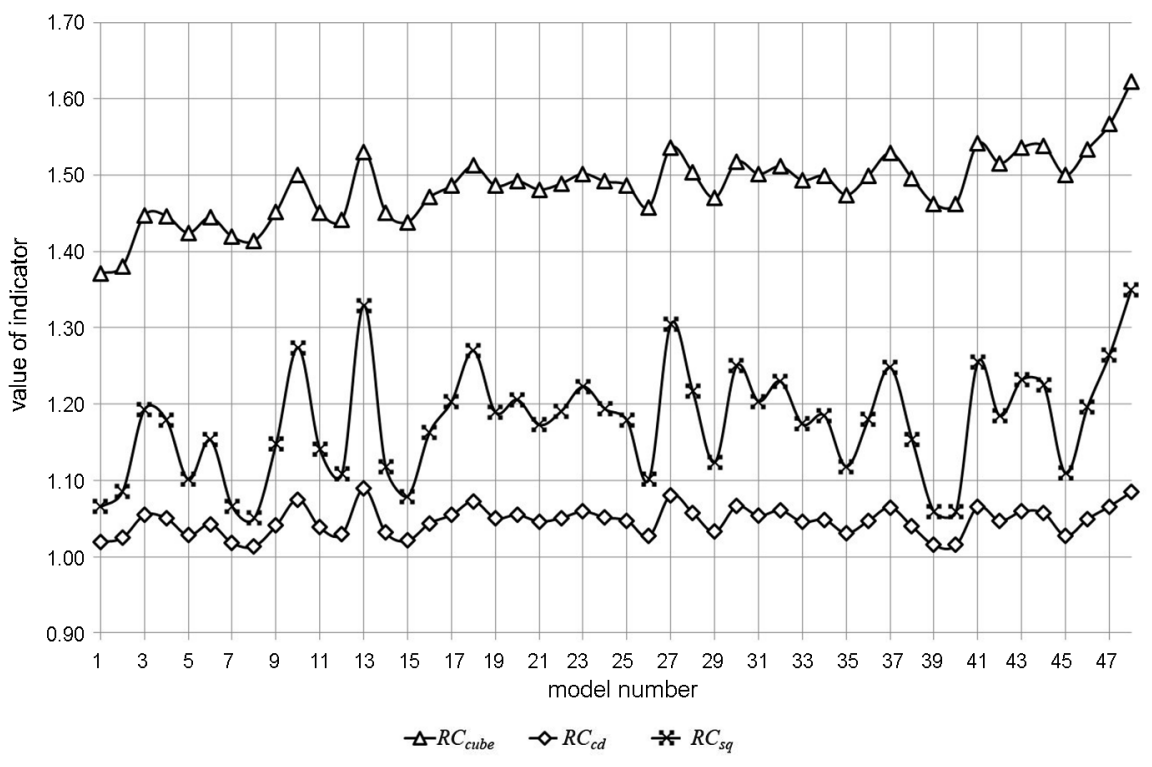

Figure 10. List of $R C_{c u b e}, R C_{c d}$ and $R C_{s q}$ indicators for 48 research models

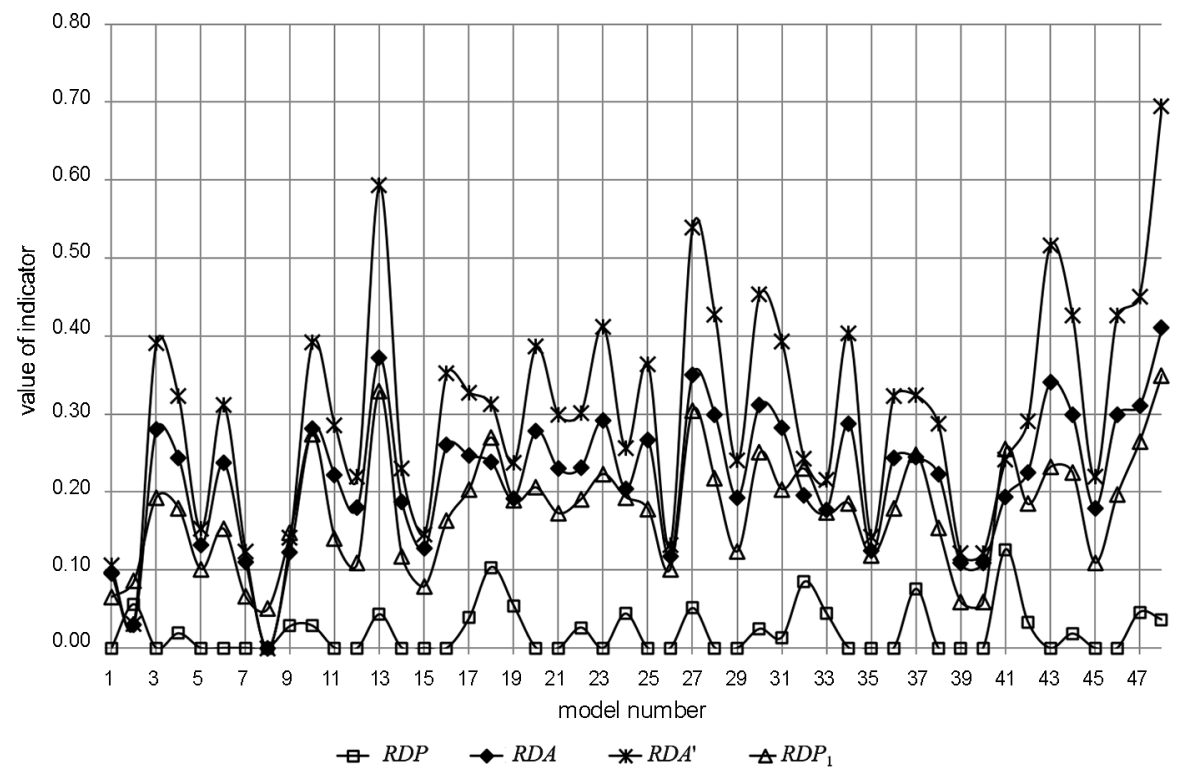

Figure 11. List of $R D P, R D A, R D A^{\prime}$ and $R D P_{1}$ indicators for 48 research models

\section{Conclusions}

The analysis of determinants of all buildings and designs selected for research indicates the rationale of introducing the $R C_{c d}$ indicator as definitely better reflecting the building's compactness than the $R C_{c u b e}$ indicator. It is worth noting that the passive energy-saving building, in a visual assessment having optimal dimensions (Figure 9), has the $R C_{c u b e}=1.21$. The value of the $R C_{c d}$ indicator is equal to 1.00 , which means that it is a building with perfect compactness. The values of $R D A=0.00$ and $R D P_{1}=$ 0.00 confirm the optimal compactness of the house "Valletta Passive LDP06". In the other cases, small deviations of the $R C_{c d}$ indicator indicate the percentage deviation of the compactness (imperfection) from the compactness of the reference solid. They range from $2 \%$ to $4 \%$.
All the analyzed examples confirm that the $R C_{c d}$ indicator is a simple good measure of the compactness of buildings. The value 1 of this indicator is a limit value and means that the building has the best compactness. According to the authors, it is the most important indicator introduced in this paper. However, all together, despite the total dependence of some $\left(R D P_{1}\right.$ and $R C_{s q} ; R D A^{\prime}$ and $\left.R D A\right)$ or limit dependence $\left(R C_{c d}\right.$ and $\left.R C_{s q}\right)$, they are a tool for testing the compactness of buildings.

Although the subject of the paper is devoted to buildings constructed on a rectangular polygon plan, it should be emphasized that all indicators, except $R D P$ and $R D A\left(R D A^{\prime}\right)$, are universal; their definitions have not been claimed to concern rectangular polygons. 


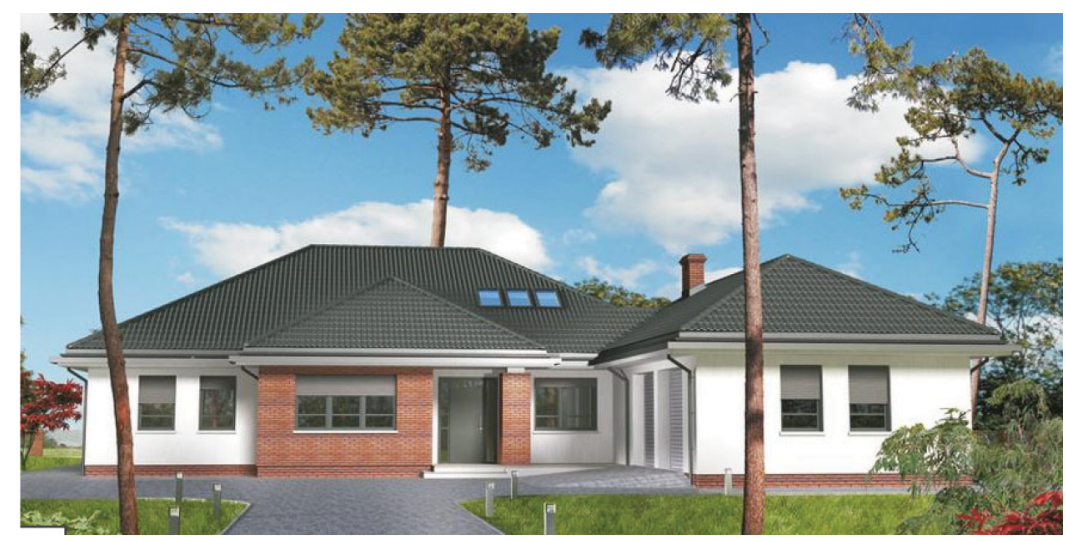

$48 \mathrm{M} 113$
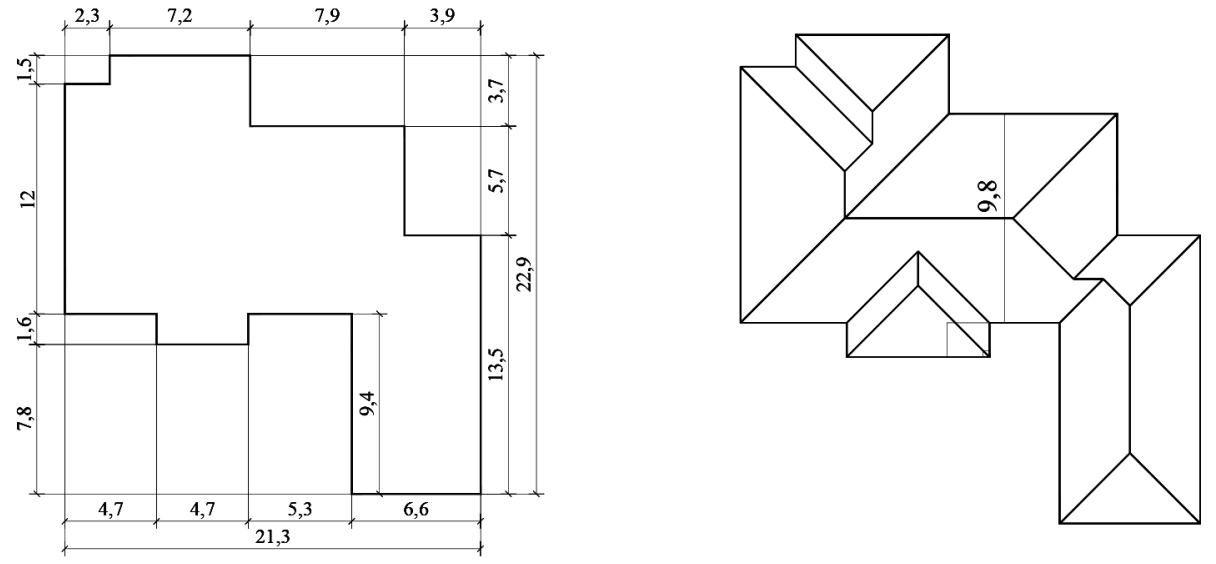

Figure 12. Research model No 48 (model M113) (Projekty Muratordom, 2018)

$R D A\left(R D A^{\prime}\right)$ and $R D P$ indicators have a very intuitive geometric interpretation. Each building whose plan is a rectangular polygon different from a rectangle has the same effect that its $R D A\left(R D A^{\prime}\right)$ values are greater than zero.

Proposed indicators allow for a description of the compactness of the solid (building model) with an indication (in percentage points) of the deviation from the real ideal solid (or figure in the plane). The introduced geometric determinants of solids may be useful in the initial phase of searching for satisfactory design solutions. Previously, research should be carried out by calculating the construction costs (raw shell of a closed building) and energy consumption (for the same types of building partitions) to create an appropriate information base. Such results will be adequate to the types of materials and climatic conditions.

\section{Funding}

This work was supported by Bialystok University of Technology grant $\mathrm{S} / \mathrm{WBiIS} / 4 / 16$.

\section{Author contributions}

EK is the originator of the paper topic. He formulated all the indicators at the paper and derived all the formulas. He made Figures 1, 2, 3 and developed and made symbolic drawings for Tables 1 and 2. He made calculations and developed
Table 4. He wrote the paper. AŻ developed figures 7, 8 , 9 and Table 6 and performed the calculations accordingly. PD made photographs on Figures 4, 5, 6 and inventories of existing buildings. He made calculations and developed Figures 4, 5, 6, 10 and 11 and Table 5. He developed projection models of 48 buildings, made calculations and made the Figure 12.

\section{Disclosure statement}

Authors have no competing interests.

\section{References}

Adamski, M. (1994). Optimization of the form a building with arbitrary base. Engineering Transactions, 42(4), 1632-1643. https://doi.org/10.1016/j.buildenv.2006.02.004

Allouhi, A., El Fouih, Y., Kousksou, T., Jamil, A., Zeraouli, Y., \& Mourad, Y. (2015). Energy consumption and efficiency in buildings: current status and future trends. Journal of Cleaner Production, 109, 118-130. https://doi.org/10.1016/j.jclepro.2015.05.139

Almumar, M. M. S. (2016). Understanding building compactness entity, definition and concept of assessment. International Transaction Journal of Engineering, Management, \& Applied Sciences \& Technologies, 7(3).

Behsh, B. (2002). Building form as an option for enhancing the indoor thermal conditions. In $6^{\text {th }}$ Nordic Symposium "Building Physics 2002" (Session 18: Indoor Environment 2). 
Bostancioğlu, E. (2010). Effect of building shape on residential building's construction, energy and life cycle costs. Architectural Science Review, 53(4), 441-467.

https://doi.org/10.3763/asre.2009.0040

Bribieska, E. (2000). A measure of compactness for 3D shapes. Computer and Mathematics with Applications, 40(10-11), 1275-1284. https://doi.org/10.1016/S0898-1221(00)00238-8

Depecker, P., Menezo, C., Virgone, J., \& Lepers, S. (2001). Design of buildings shape and energetic consumption. Building and Environment, 36(5), 627-635.

https://doi.org/10.1016/S0360-1323(00)00044-5

Dz. U. poz. 1422. (2015). Obwieszczenie Ministra Infrastruktury $i$ Rozwoju $z$ dnia 17 lipca 2015 r. w sprawie ogłoszenia jednolitego tekstu rozporzadzenia Ministra Infrastruktury $w$ sprawie warunków technicznych, jakim powinny odpowiadać budynki $i$ ich usytuowanie [Decree of the Minister of Infrastructure and Development of 17 July 2015 on the publication of a uniform text of the Regulation of the Minister of Infrastructure on the technical conditions to be met by buildings and their location].

Elango, M., \& Devadas, M. D. (2014). Multi-criteria analysis of the design decisions in architectural design process during the pre-design stage. International Journal of Engineering and Technology, 6(2), 1033-1046.

Feather, A. L. (1996). Circular or rectangular ground plans: Some costs and benefits. Nebraska Anthropologist, 13, 57-66.

Fokin, K. F. (2006). Stroitel'naya teplotekhnika ograzhdayushchikh chastey zdaniy [Building heat engineering of the enclosing parts of buildings]. Moscow: AVOK-PRESS Publ.

Geletka, V., \& Sedláková, A. (2012). Shape of buildings and energy consumption. Technical Transactions. Civil Engineering, 3.

Hemsath, T. L., \& Bandhosseini, K. A. (2015). Building design with energy performance as primary agent. Energy Procedia, 78, 3049-3054. https://doi.org/10.1016/j.egypro.2015.11.722

Jedrzejuk, H., \& Marks, W. (2002). Optimization of shape and functional structure of buildings as well as heat source utilisation. Partial problem solution. Building and Environment, 37(11), 1037-1043.

https://doi.org/10.1016/S0360-1323(01)00099-3

Koźniewski, E. (2007). Geometria dachów. Teoria i zastosowanie [Geometry of roofs. Theory and applications]. Białystok: Wydawnictwo Politechniki Białostockiej.

Koźniewski, E. (2015). Rectangular polygons and its shape parameters. The Journal Biuletyn of Polish Society for Geometry and Engineering Graphics, 27, 9-15.

Koźniewski, E., Żaba, A., \& Dudzik, P. (2015). The compactness indicators of solids. In Proceedings of $22^{\text {nd }}$ Conference "Geometry Graphics Computer" (pp. 52-55). Kraków, Politechnika Śląska, Ośrodek Geometrii i Grafiki Inżynierskiej.

Lim, H. S., \& Kim, G. (2018). Analysis of energy performance on envelope ratio exposed to the outdoor. Advances in Civil Engineering, 3, ID 7483619, 1-10.

https://doi.org/10.1155/2018/7483619
Lipinscy Domi. (2018). Retrieved from https://lipinscy.pl/projekt/ Mahdavi, A., \& Gurtekin, B. (2002). Shapes, numbers, and perception: Aspects and dimensions of the designperformance space. In Proceedings of the $6^{\text {th }}$ International Conference: Design and Decision Support Systems in Architecture (pp. 291-300). Netherlands.

Mahdavi, A., \& Gurtekin, B. (2001). Computational support for the generation and exploration of the design-performance space. In Proceedings of IBPSA Conference (pp. 669-676). Rio de Janeiro, Brazil.

Markus, T. A., \& Morris, E. N. (1980). Buildings, climate and energy. London: Pitman Publishing Limited.

McKeen, P., \& Fung, A. S. (2014). The effect of building aspect ratio on energy efficiency: A case study for multi-unit residential buildings in Canada. Buildings, 4(3), 336-354. https://doi.org/10.3390/buildings4030336

Menkhoff, H., Blum, A., Trykowski, M., Wente, E., \& Zapke, W. (1983). Energetisches Bauen. Eergiewirtschaftliche Aspecte zur Planung und Gestaltung von Wohnegebauden. Schriftenreiche "Bau- und Wohnforschung" des Bundesministers fur Raumordnung, 04.086/1983.

Neufert, N., \& Neufert, P. (2012) Architects' data (4 $4^{\text {th }}$ ed.). WilleyBlackwell. https://doi.org/10.1007/978-3-8348-2247-5

Ourghi, R., Al-Anzi, A., \& Krarti, M. (2007). A simplified analysis method to predict the impact of shape on annual energy use for office buildings. Energy Conversion and Management, 48(1), 300-305.

https://doi.org/10.1016/j.enconman.2006.04.011

Parasonis, J., Keizikas, A., Endriukaitytè, A., \& Kalibatienè, D. (2012). Architectural solutions to increase the energy efficiency of buildings. Journal of Civil Engineering and Management, 18(1), 71-80. https://doi.org/10.3846/1392373 0.2011 .652983

Pessenlehner, W., \& Mahdavi, A. (2003). Building morphology, transparence, and energy performance. In Eighth International IBPSA Conference (pp. 1025-1032). Eindhoven, Netherlands.

Projekty Muratordom. (2018). Retrieved from https://projekty. muratordom.pl/projekt_wokol-kominka-etap-ii-zwentylacja-mechaniczna-i-rekuperacja,2192,0\%2C0.htm

Raof, B. Y. (2017). The correlation between building shape and building energy performance. International Journal of Advanced Research, 5(5), 552-561. https://doi.org/10.21474/IJAR01/4145

Rodrigues, E., Amaral, A. R., Gaspar, A. R., \& Gomes, A. (2015). How reliable are geometry-based building indices as thermal performance indicators?. Energy Conversion and Management, 101, 561-578. https://doi.org/10.1016/j.enconman.2015.06.011

Steadman, P. (2006). Why are most building rectangular?. Architectural Research Quarterly, 10(2), 119-130. https://doi.org/10.1017/S1359135506000200

Tuhus-Dubrow, D., \& Krarti, M. (2010). Genetic-algorithm based approach to optimize building envelope design for residential buildings. Building and Environment, 45(7), 1574-1581. https://doi.org/10.1016/j.buildenv.2010.01.005 